\title{
Wind Plant Capacity Credit Variations: A Comparison of Results Using Multiyear Actual and Simulated Wind-Speed Data
}

Michael Milligan

Presented at Windpower '97

Austin, Texas

June 15-18, 1997

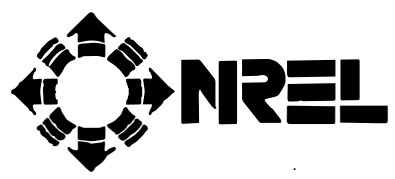

National Renewable Energy Laboratory 1617 Cole Boulevard

Golden, Colorado 80401-3393

A national laboratory of the U.S. Department of Energy Managed by Midwest Research Institute for the U.S. Department of Energy under contract No. DE-AC36-83CH10093

Work performed under task number WE712010

June 1997 


\section{NOTICE}

This report was prepared as an account of work sponsored by an agency of the United States government. Neither the United States govemment nor any agency thereof, nor any of their employees, makes any warranty, express or implied, or assumes any legal liability or responsibility for the accuracy, completeness, or usefulness of any information, apparatus, product, or process disclosed, or represents that its use would not infringe privately owned rights. Reference herein to any specific commercial product, process, or service by trade name, trademark, manufacturer, or otherwise does not necessarily constitute or imply its endorsement, recommendation, or favoring by the United States govemment or any agency thereof. The views and opinions of authors expressed herein do not necessarily state or reflect those of the United States government or any agency thereof.

Available to DOE and DOE contractors from:

Office of Scientific and Technical Information (OSTI)

P.O. Box 62

Oak Ridge, TN 37831

Prices available by calling (423) $576-8401$

Available to the public from:

National Technical Information Service (NTIS)

U.S. Department of Commerce

5285 Port Royal Road

Springfield, VA 22161

(703) $487-4650$ 


\title{
WIND PLANT CAPACITY CREDIT VARIATIONS: A COMPARISON OF RESULTS USING MULTIYEAR ACTUAL AND SIMULATED WIND-SPEED DATA
}

\author{
Michael R. Milligan \\ National Renewable Energy Laboratory \\ 1617 Cole Boulevard \\ Golden, Colorado 80401 \\ U.S.A.
}

\begin{abstract}
Although it is widely recognized that variations in annual wind energy capture can be significant, it is not clear how significant this effect is on accurately calculating the capacity credit of a wind plant. An important question is raised concerning whether one year of wind data is representative of long-term patterns.
\end{abstract}

This paper calculates the range of capacity credit measures based on 13 years of actual wind-speed data. The results are compared to those obtained with synthetic data sets that are based on one year of data. Although the use of synthetic data sets is a considerable improvement over single-estimate techniques, this paper finds that the actual inter-annual variation in capacity credit is still understated by the synthetic data technique.

\section{INTRODUCTION}

Utilities, independent power producers, or other investors in wind power plants must undertake an analysis to determine the likely cost and revenue streams for a project. The revenue from any power plant is typically provided by the sale of energy, capacity, or both. The relative levels of revenue from capacity and energy sales are often specified by contract, and will vary as a function of several variables. Some of these variables include the structure of the company that owns the power plant, the terms of the contract(s), operational practices in the control area, and characteristics of the power plant itself. In other cases, the utility may own the wind plant, but both capacity and energy must still be valued internally. Wind power plants provide an attractive alternative to other power sources because of the free, nonpolluting fuel (the wind itself) that drives the generator. On the other hand, assigning capacity credit for wind plants is complicated by the stochastic nature of the wind availability. With advances in power electronics, it is likely that wind plant operators will be able to exercise greater control over the short-term output of the plant, but this control will still be constrained by the nature of the wind resource. From an operational standpoint a wind plant operator would be able to bid capacity into a pool (or otherwise make commitments on wind power delivery) if he or she possessed an accurate wind forecast for the time period in question. The benefit of accurate wind forecasting is further described in Milligan, Miller, and Chapman (1995).

One significant weakness of most wind plant revenue-stream calculations is that interannual variability in the wind resource is not known. Typically, the developer collects wind data for one year or less. Using hourly wind-speed data, it is then possible to calculate wind power output for each hour. These data can be summarized in a variety of ways and time scales, both in terms of capacity and energy. Estimated future energy production is used as input to the financial model, which provides expected rate-of-return and other financial measures that are used to decide whether or not to build the wind plant. However, the uncertainty that is attached to the estimated wind energy is rarely calculated, and even then, is not likely to be accurate. This implies that the potential wind plant investor is exposed to the risk of basing an investment decision on an unusual wind-year. In order to overcome this difficulty, an analysis of nearby long-term wind data from airports or other meteorological sites can be pursued. This may be the best way to proceed given a lack of measured wind data at the site. The risk from limited data cuts both ways. First, the measured data could be 
from a year with unusually low wind, so a good long-term wind site may not be developed. Alternatively, if the measured year has an unusually high wind speed, then the realized revenue stream will fall short of the projected stream.

In this paper a 13-year data set is used to calculate the range of energy and capacity-credit values from the actual data. Representative years are selected on which a Markov wind-speed simulator tool is applied. The wind-speed simulator generates multiple wind-speed series based on the time-scale properties of the original data, allowing for the analysis of plausible wind-speed variations and their effect on capacity credit and other measures of interest.

\section{CHARACTERISTICS OF THE 13-YEAR DATA SET}

The data used for this analysis is from an air-quality monitoring site in North Dakota. Data was collected for a 13-year period beginning in 1980. This particular site would not likely be chosen for a wind plant because of the relatively low annual average wind speed. However, until long-term data such as this does become available at potential wind-plant sites, it is useful to examine the data at hand. To compensate for the low wind speed, the data were scaled so that the average annual wind speed matched that at Minot, ND (Sandusky, et. al., 1983). Figure 1 shows the normalized variation in annual energy production for a fictitious $100 \mathrm{MW}$ wind plant. The highest annual energy production for the 13-year period occurred in 1988. During 1981 and 1983 the wind energy capture was approximately $73 \%$ of the 1988 level. Over the 13 -year period, the average energy capture is about $85 \%$ of the maximum, with a standard deviation of 8.7 .

Although there is clearly significant variation from year to year, there is a striking variation that occurs when the data is viewed on a monthly basis. Figure 2 plots the monthly energy for three selected years: 1980, 1986, and 1990. These years were chosen to represent mean plus or minus one standard deviation of the annual wind energy production as shown in Figure 1. The months of March and April show extremely high variation in energy output. The month of December exhibits the most agreement between monthly energy levels.

Figure 3 was constructed by taking the maximum, minimum, and mean energy production from the 13-year data set for each month. For example, the maximum series in the graph represents a composite that consists of the maximum energy taken from all 13 January energy values, the maximum from all February energy values, and so on.

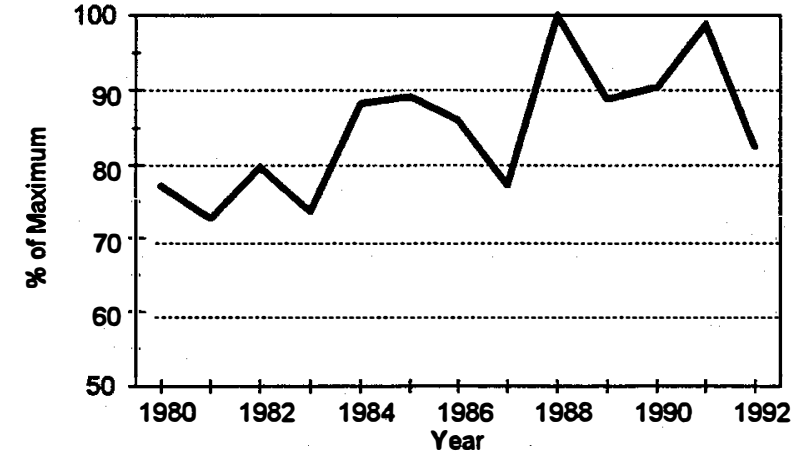

FIGURE 1. ANNUAL ENERGY PRODUCTION

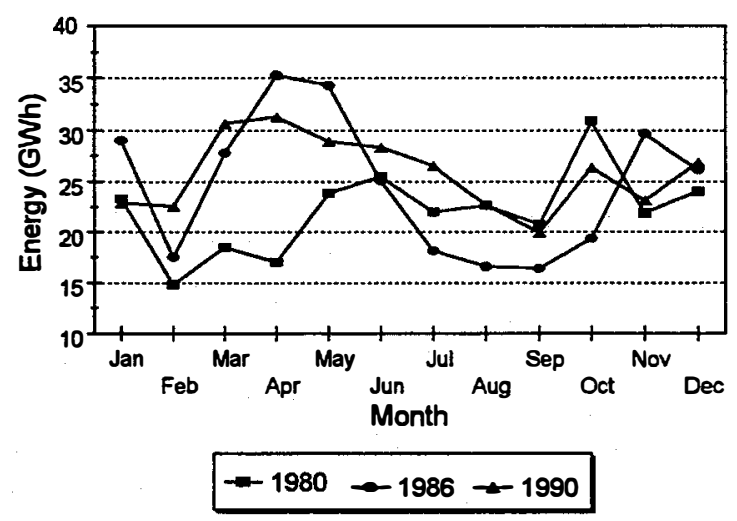

FIGURE 2. VARIATIONS IN MONTHLY ENERGY, SELECTED YEARS 


\section{MODELING WTTH THE ACTUAL DATA}

After calculating the energy production for the 13 years of data, I calculated the capacity credit for each year for a $100 \mathrm{MW}$ wind plant. Elfin is a production-cost/reliability model that has been described in another publication (Milligan, 1996a), and is a product of the Environmental Defense Fund. The model used a load duration curve approximation to calculate costs of energy based on an optimal dispatch strategy that minimizes costs. The model can also be used to calculate capacity credit, which is based on a system reliability index such as loss-of-load expectation (LOLE). Using actual utility load and generator data for Tri-State Generation \& Tranmission, Association, Incorporated (Milligan \& Parsons, 1997), the model was used to calculate the effective load carrying capability (ELCC) for each year of wind data, using a target LOLE of 1 day in 10 years. Figure 4 illustrates the results of these calculations, along with the graph $f$ annual energy production for ease of comparison. As indicated in the diagram, capacity credit and energy production tend to move together, but not always. The reason is that higher energy production may occur in hours of high reliability. In this case, the capacity is not provided when it is most needed to support system reliability and causes a lesser positive impact on capacity credit. This effect was also observed by Milligan and Parsons (1997). As indicated in the figure, there is a relatively high correlation between energy production and capacity credit.

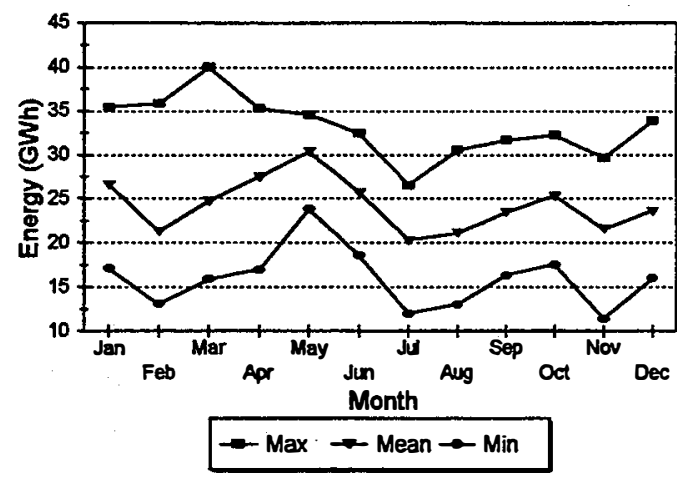

FIGURE 3. MAXIMUM, MINIMUM, AND MEAN MONTHLY ENERGY

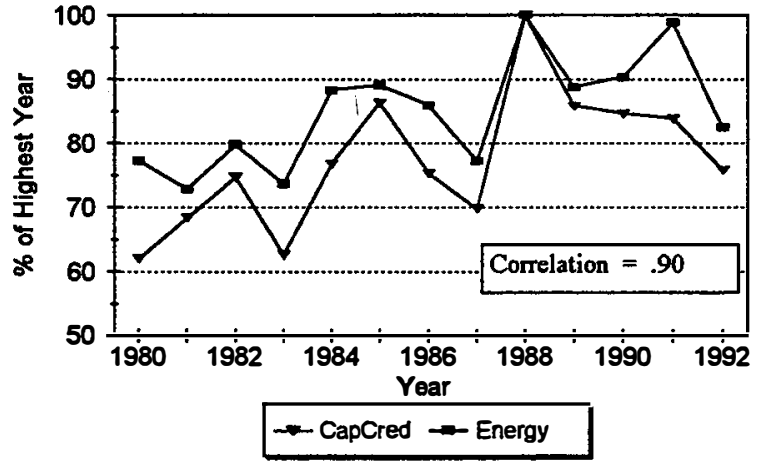

FIGURE 4. CAPACITY CREDIT AND ENERGY FOR 13 YEARS

Table 1 shows the variation in energy and capacity credit, as measured by the coefficient of variation (COV), defined by the ratio of the standard deviation to the mean. The ELCC has a higher variation than energy because relatively small shifts in the timing of wind energy delivery can have a significant impact on system reliability, and thus the capacity credit of the wind plant.

TABLE 1. CAPACITY CREDIT AND ENERGY FROM ACTUAL DATA

\begin{tabular}{|l|r|r|r|r|r|}
\hline Data & Average & $\begin{array}{l}\text { Standard } \\
\text { Deviation }\end{array}$ & Maximum & Minimum & $\begin{array}{l}\text { Coefficient of } \\
\text { Variation (\%) }\end{array}$ \\
\hline Energy (GWh) & 291.7 & 30.0 & 343.3 & 250.0 & 10.3 \\
\hline ELCC (MW) & 39.1 & 5.4 & 50.5 & 31.3 & 13.8 \\
\hline
\end{tabular}




\section{MODELING WITH THE SIMULATED DATA}

Using the actual wind-speed data from each of the 13 years, I selected 3 years to represent high-wind (1990), low-wind (1980), and mean-wind (1986) cases. The high and low years approximate one standard deviation above and below the mean, respectively. Using these three years, a Markov wind-speed simulation tool was used to generate 100 time-series of wind power for each selected year. This process has been described in Milligan (1996b) and resulted in a total of 300 wind power time-series. Figures 5 and 6 illustrate two of the state-transition matrices calculated from the actual data for July 1980 and July 1981, respectively. The 3 large spikes at the high wind-speeds in Figure 6 illustrates a much higher probability of high-wind events than in 1980. The large variation in state-transition matrices is consistent with that found in the wind-speed and windpower data illustrated by some of the previous graphs.

State-transition matrices such as those shown in Figures 5 and 6 were used to generate the synthetic wind-speed data for the 300 time-series. Using actual wind-speed data, a state-transition matrix was calculated for each month. The resulting distribution was sampled to create a large number of time-series of wind-speed data. Each of these series consists of one year of hourly wind-speed data which was then used to calculate hourly power output for the hypothetical wind plant. Each of these 300 data series was then processed by the Elfin production-cost model. Elfin was executed repeatedly for various utility load levels to determine the ELCC of each of the 100 wind power time-series for each of the 3 selected years. The discussion separately considers each of the three years, followed by some observations of the combined results.

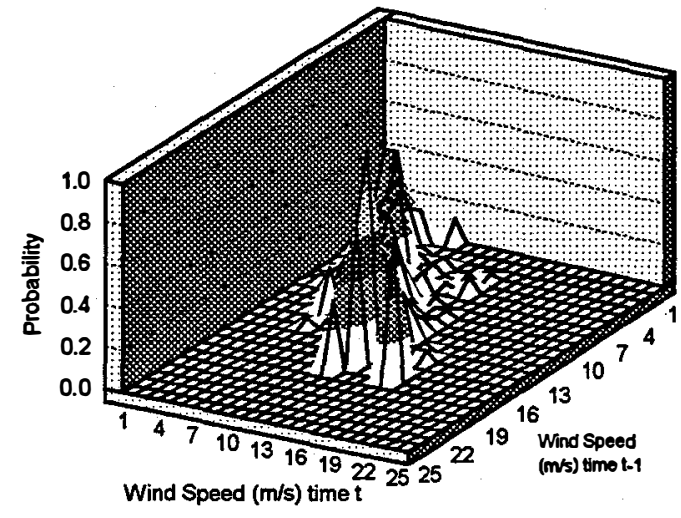

FIGURE 5. STATE TRANSITION MATRIX, JULY, 1980

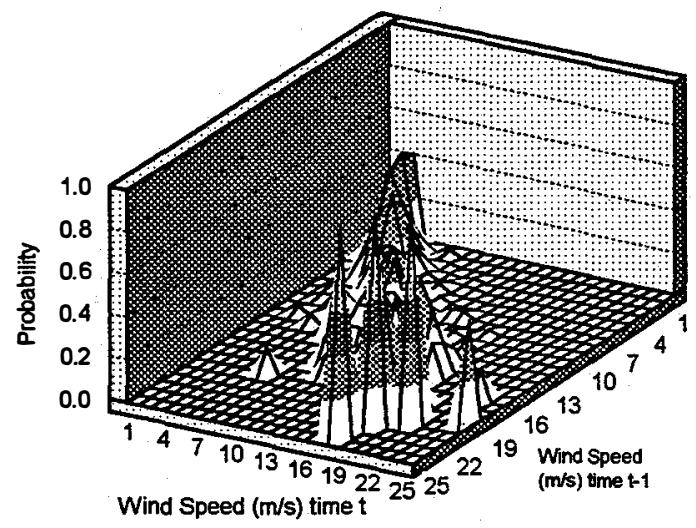

FIGURE 6. STATE TRANSITION MATRIX JULY, 1981

\section{HIGH-WIND YEAR RESULTS}

Figure 7 shows the results for the high-wind year, 1990. The graph shows the ELCC results for each of the 100 cases for the year. The average ELCC for the 100 cases is $42.3 \mathrm{MW}$, which very closely approximates the ELCC that was calculated from the actual data, 42.7 MW. Using the Markov approach does result in years with varying capacity credits, in this case ranging from a minimum of $30.5 \mathrm{MW}$ to a maximum of $52.5 \mathrm{MW}$ Both the maximum and minimum are close to those calculated from the actual data, as displayed above in Table 1. Figure 8 shows the convergence of the high-wind simulations. The convergence factor is the ratio of the cumulative standard deviation to the cumulative mean (see Milligan, 1996b). Inspection of the convergence factor indicates that the stability of the results is still in doubt until about 70 Markov iterations 


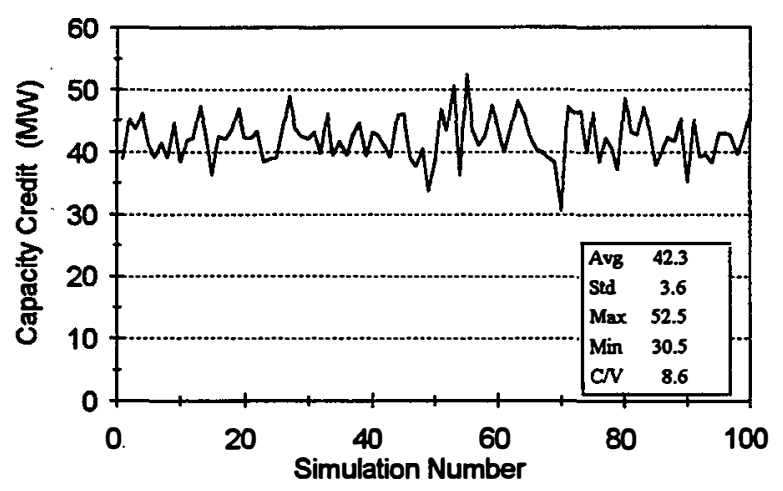

FIGURE 7. ELCC RESULTS FROM HIGHWIND YEAR, 1990

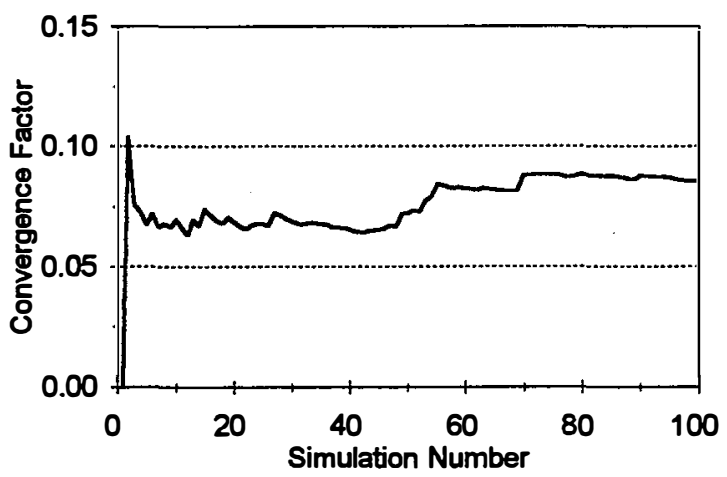

FIGURE 8. CONVERGENCE OF ELCC RESULTS, 1990

have been performed. It would be useful to provide the model with convergence criteria instead of a fixed number of iterations. However, as discussed in Milligan (1996b) this cannot be accomplished with the Elfin model. Billinton, Chen, and Ghajar (1996) find that convergence is achieved after approximately 6,000 iterations using an integrated auto-regressive moving-average (ARIMA) process to model wind speed. Figures 9 and 10 show further results from the 1990 simulations. Figure 9 . illustrates the frequency distribution of the ELCC values. The bin sizes correspond to the standard deviation of ELCC, and the middle bin contains all ELCC values within $1 / 2$ standard deviation either side of the mean. Figure 10 shows the energy obtained by the Markov simulation process for each of the 100 cases. As was the case with the actual data, there is more variation in ELCC than energy. The mean energy value is very close to the actual energy for 1990, as one would expect.

\section{MEAN-WIND YEAR RESULTS}

Figure 11 shows the capacity credit results for the mean-wind year. As expected, the average, maximum, and minimum ELCC values are less than those of the high-wind year. The coefficient of variation is somewhat higher than the high-wind case because of a smaller mean and slightly higher standard deviation. Figure 12

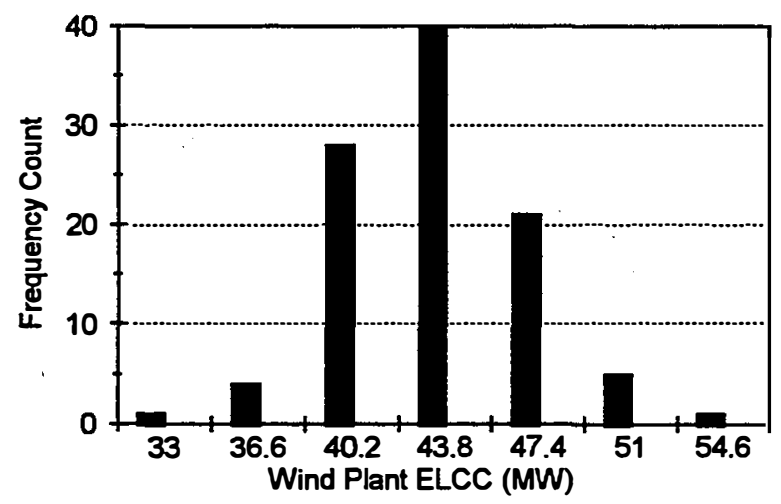

FIGURE 9. ELCC FREQUENCY DISTRIBUTION, 1990 SIMULATIONS

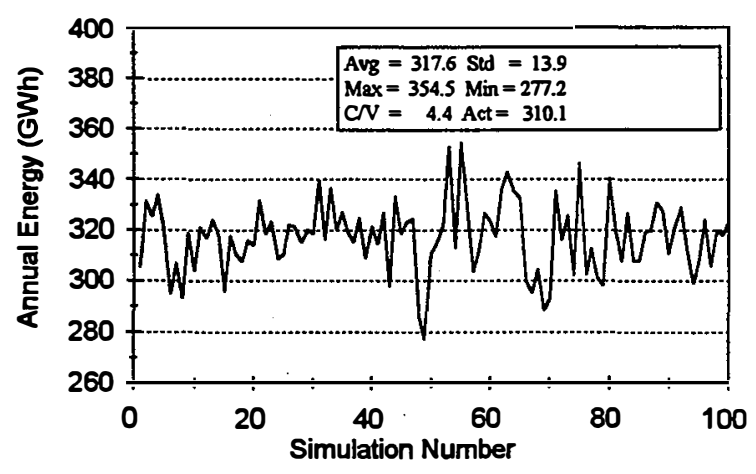

FIGURE 10. ENERGY RESULTS FROM HIGH-WIND YEAR, 1990 


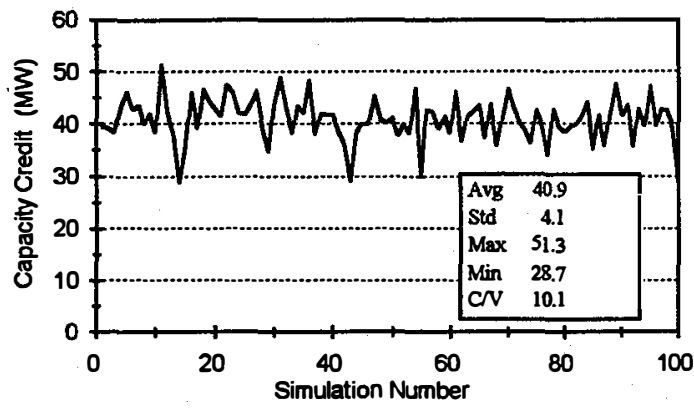

FIGURE 11. ELCC RESULTS FROM MEAN-WIND YEAR, 1986

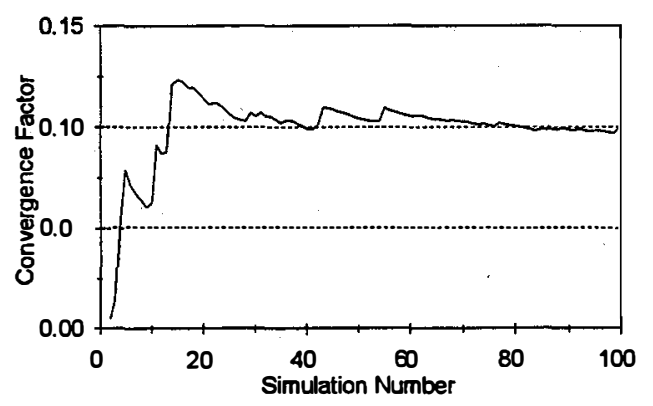

FIGURE 12. CONVERGENCE OF ELCC RESULTS, 1986

shows the convergence factor for 1986. Relative stability appears to be reached after about 70 iterations-about the same point as for the high-wind year.

Figures 13 and 14 show the ELCC distribution and energy results from 1986. With the exception of a few outliers in the left-most bin, the shape of the distribution is nearly symmetrical. The mean, maximum, and minimum energy values are less than those of the high-wind year, as expected.

\section{LOW-WIND YEAR RESULTS}

Figures 15-18 show the results from 1980, the low-wind year. The average ELCC value for this year is about 4.5 MW less than the mean case. The results from the low-wind case parallel those of the other cases, with correspondingly lower ELCC and energy values.

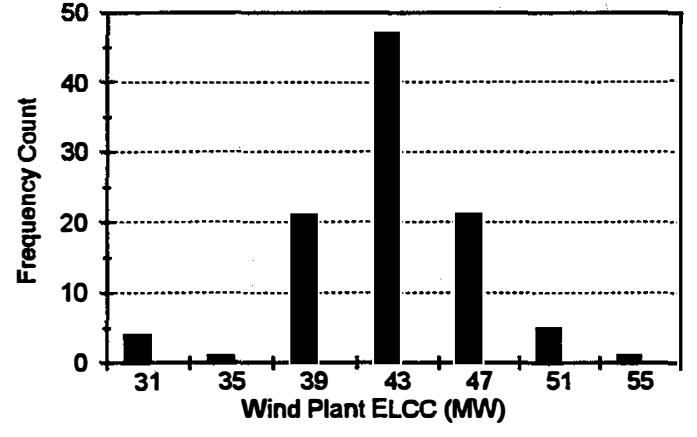

FIGURE 13. ELCC FREQUENCY DISTRIBUTION, 1986 SIMULATIONS

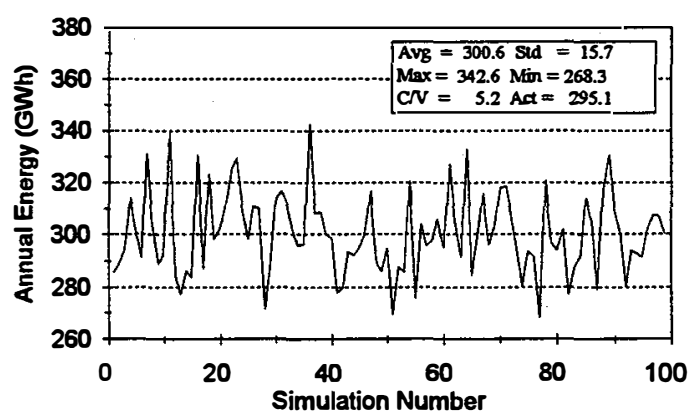

FIGURE 14. ENERGY RESULTS FROM MEAN-WIND YEAR, 1986 


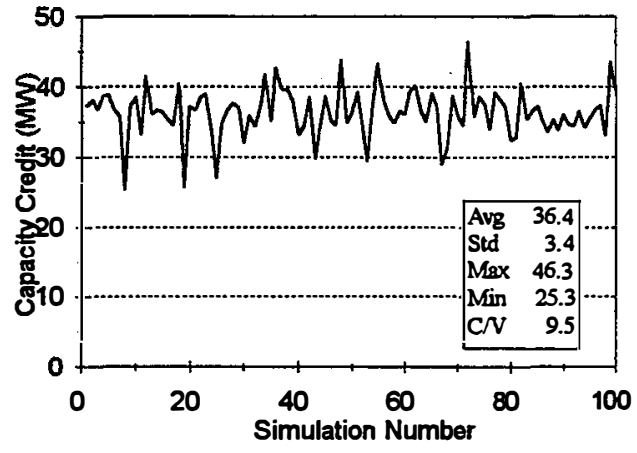

FIGURE 15. ELCC RESULTS FROM LOW-WIND YEAR, 1980

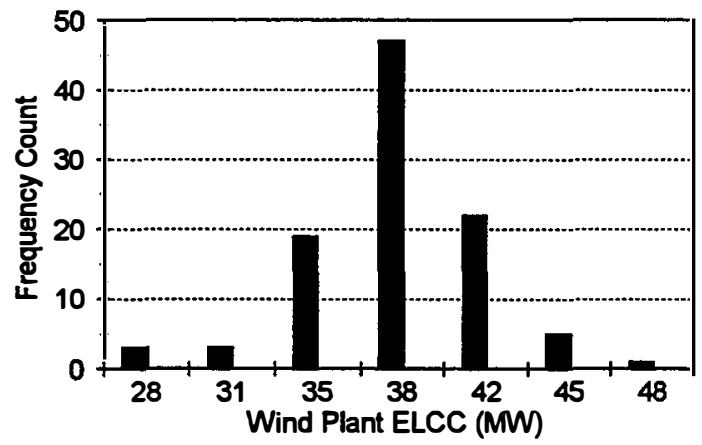

FIGURE 17. ELCC FREQUENCY DISTRIBUTION, 1980 SIMULATIONS

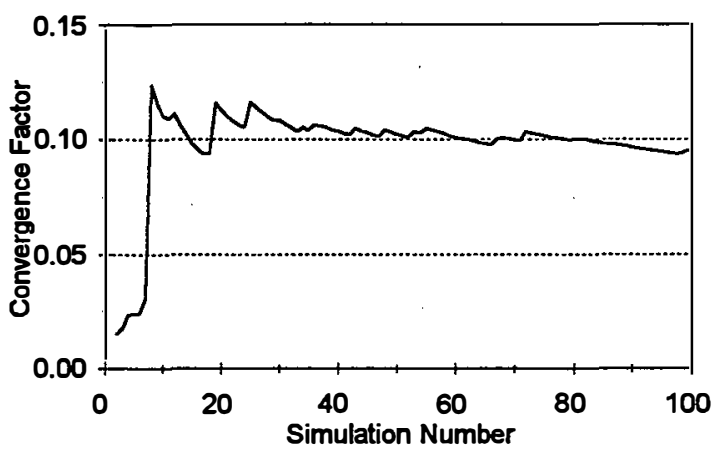

FIGURE 16. CONVERGENCE OF ELCC RESULTS, 1980

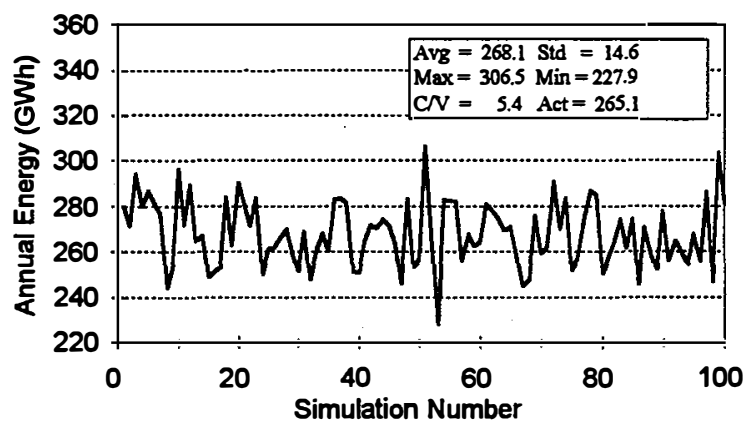

FIGURE 18. ENERGY RESULTS FROM MEAN WIND-YEAR, 1980

\section{COMBINED RESULTS}

Tables 2 and 3 gather the results from the various simulations discussed in the previous sections. Table 2 shows the ELCC results for each of the high-, mean-, and low-wind years. The actual data results are included in the first row for convenience. The variation of the simulated ELCC values as measured by the range overestimates the variation in the actual data. Conversely, the coefficient of variation from the simulated data sets underestimates the variation in the actual data set. The simulated energy ranges in Table 3 all significantly understate the variation in the actual data, as do the coefficients of variation.

What are the implications of this work? If data has been collected for a single year that nearly matches a longterm mean year, then the Markov approach does a reasonably good job of predicting the likely range of ELCC values, but underpredicts variations in annual energy. To accurately predict energy variations another method would be required.

If a single year of wind data is collected, the important question is whether that is a typical-, high-, or low-wind year. In some cases data for the measured year can be compared with other long-term data records to establish 
TABLE 2. ELCC SIMULATION COMPARISONS

\begin{tabular}{|l|r|r|r|r|r|r|}
\hline Wind Data & Average & $\begin{array}{r}\text { Standard } \\
\text { Deviation }\end{array}$ & Maximum & Minimum & Range & C/V (\%) \\
\hline Actual & 39.1 & 5.4 & 50.5 & 31.3 & 19.2 & 13.8 \\
\hline High-Wind Year & 42.3 & 3.6 & 52.5 & 30.5 & 22.0 & 8.6 \\
\hline Mean-Wind Year & 40.9 & 4.1 & 51.3 & 28.7 & 22.6 & 10.1 \\
\hline Low-Wind Year & 36.4 & 3.4 & 46.3 & 25.3 & 21.0 & 9.5 \\
\hline
\end{tabular}

TABLE 3. ENERGY SIMULATION COMPARISONS

\begin{tabular}{|l|r|r|r|r|r|r|}
\hline Wind Data & Average & $\begin{array}{r}\text { Standard } \\
\text { Deviation }\end{array}$ & Maximum & Minimum & Range & C/V (\%) \\
\hline Actual & 291.7 & 30.0 & 343.3 & 250.0 & 93.3 & 10.3 \\
\hline High-Wind Year & 317.6 & 13.9 & 354.5 & 277.2 & 77.3 & 4.4 \\
\hline Mean-Wind Year & 300.6 & 15.7 & 342.6 & 268.3 & 74.3 & 5.2 \\
\hline Low-Wind Year & 268.1 & 14.6 & 306.5 & 227.9 & 78.6 & 5.4 \\
\hline
\end{tabular}

how the measured year compares to a longer period. Once this determination is made, the Markov method could be used to calculate the estimated variations.

Several caveats should also be pointed out. First, these results may not be robust to other wind sites. The North Dakota data used in this report does not have a significant diumal component, as the wind is primarily caused by synoptic-scale weather events. This data was obtained from an air-quality monitoring site that would not be utilized for a wind power plant. Second, it is likely that a significantly longer data set should be used to establish the wind-speed characteristics of a site. Finally, all capacity credit calculations are sensitive to the correlation between the utility load and wind resource and to the specific utility resource mix during peak and off-peak periods. ELCC is also sensitive to the level of the risk-target chosen by the utility management and whether the LOLE or energy-not-served or other reliability measure is chosen as the appropriate risk measure.

\section{CONCLUSIONS}

This paper has presented a method to estimate capacity credit variations of wind power plants, using synthetic data generated with a Markov process. The state-transition matrices are based on actual wind-speed data. Although there is room for improvement, the method does a reasonably good job of providing an estimate of capacity credit, as measured by ELCC. This method is not particularly effective for estimating energy variations, an area that needs further investigation. 


\section{ACKNOWLEDGMENTS}

This work was supported by the United States Department of Energy under contract DE-AC36-83CH10093. The author gratefully acknowledges the helpful discussions and comments provided by Thomas Brookman of the Orlando Utilities Commission, Alan Miller of Problem Solvers International, and Brian Parsons and Kristin Tromly of the National Renewable Energy Laboratory. Thanks also to Mark Graham of Tri-State Generation and Transmission Association, Incorporated, for providing load and generator data.

\section{REFERENCES}

Billinton, R. H. Chen, and R. Ghajar (1996). “A Sequential Simulation Technique for Adequacy Evaluation of Generating Systems Including Wind Energy." Presented at IEEE/PES Winter Meeting, January 21-25, 1996. Baltimore, Maryland.

Milligan, M., A. Miller, and F. Chapman (1995). "Estimating the Economic Value of Wind Forecasting to Utilities." Presented at Windpower '95, March 27-31, 1995; Washington, DC. NREL/TP-441-7803. Golden, Colorado: National Renewable Energy Laboratory.

Milligan, M. (1996a). Alternative Wind Power Modeling Methods Using Chronological and Load Duration Curve Production Cost Models. NREL/TP-441-8171. Golden, Colorado: National Renewable Energy Laboratory.

Milligan, M. (1996b). "Variance Estimates of Wind Plant Capacity Credit." Presented at Windpower '96, June 23-27, 1996; Denver, Colorado. NREL/TP-440-21311. Golden, Colorado: National Renewable Energy Laboratory.

Milligan, M. and B. Parsons (1997). "A Comparison and Case Study of Capacity Credit Algorithms for Intermittent Generators." Presented at Solar '97, April 27-30, 1997; Washington, DC. NREL/CP-440-22591. Golden, Colorado: National Renewable Energy Laboratory.

Sandusky, W., J. Buck, D. Renné, D. Hadley, O. Abbey, S. Bradymire, J. Gregory (1983). Candidate Wind Turbine Generator Site Cumulative Meteorological Data Symmary and Data for January 1982 Through September 1982. 'Pacific Northwest Laboratory, Richland, Washington. PNL-4663. 